\title{
Virtual Mathematics Education during COVID-19: An Exploratory Study of Teaching Practices for Teachers in Simultaneous Virtual Classes
}

\author{
Faisal Aloufi \\ Ministry of Education, Bukayriyah Education, Kingdom of Saudi Arabia \\ https://orcid.org/0000-0002-2236-5604 \\ Ibrahim AL-Hussain Khalil \\ University of Bisha, Kingdom of Saudi Arabia \\ https://orcid.org/0000-0002-3103-7549 \\ Abdelkader Mohamed Abdelkader Elsayed \\ College of Arts \& Applied Sciences, Dhofar University, Oman \\ https://orcid.org/0000-0001-6882-4100 \\ Yousef Wardat \\ Higher Colleges of Technology, United Arab Emirates University, UAE, Alain \\ https://orcid.org/0000-0003-2370-9808
}

\author{
Ahmed AL-Otaibi \\ Ministry of Education, Taif Education, Kingdom of Saudi Arabia \\ https://orcid.org/0000-0002-0346-5079
}

\begin{abstract}
The current study has aimed to identify the status of teaching mathematics in simultaneous virtual classes, in the light of the Covid 19 pandemic, by uncovering the teaching practices in the fields of lesson planning, teaching the new mathematical knowledge, classroom management, and raising the level of interaction, and that of evaluation. The descriptive approach was used in this study, and a random sample, which consisted of 385 mathematics teachers in the Qassim Education Department, was chosen during the first semester of the academic year $2020 / 21$. The questionnaire was the tool used to collect the data after confirming the validity and the reliability thereof. The results of the study showed that the status of teaching mathematics in simultaneous virtual classes in the light of the Covid 19 pandemic was at a high level (3.80/5), according to the respondents' point of view. The results were respectively as follows: planning "high" 3.87; teaching new mathematical knowledge high "3.81"; the evaluation at a high degree of 3.80; and class management, as well as raising the level of interaction at a high degree of 3.67. The results of the study have revealed that there is a discrepancy in some
\end{abstract}


practices, a matter which requires the identification of the training needs of mathematics male and female teachers in the field of e-learning in virtual classes, such as diversifying the methods of receiving students' responses to activities (chatting - WhatsApp --... etc.); the use of electronic participatory learning strategies in building and organizing the work of cooperative learning groups, employing electronic communication applications in providing reinforcement and feedback to students, employing electronic sports activities in presenting the lesson, and by using virtual engineering tools, while solving mathematical problems.

Keywords: mathematics education; simultaneous virtual classes; teaching practices; Covid-19 pandemic

\section{Introduction}

The teacher is the cornerstone of the educational process, as well as the pillar of every social and educational reform. The quality of education is largely related to the quality of the curriculum and the quality of the teachers, who implement it (Alarabi \& Wardat, 2021). If a nation wants to progress and keep abreast of cognitive development, it must pay attention and heighten the level of the teacher, and advance the level of the profession, in which the roles of the teacher have changed, as well as the requirements of the era, and the aspirations of the future (Jarrah et al., 2020).

Mathematics teachers are considered to be the main pillars in the teaching and learning process of mathematics; and although they are just one of its inputs, they have an effective role to play; and they even specify the quality and quantity thereof (Abdallah \& Wardat, 2021). Once entering the classroom and standing in front of the students, the teacher is the only one able to invest all the available resources, through the planning of the lessons, designing the learning environment, providing multiple sources and diversification of the teaching methods, in addition to directing the students to learn a particular lesson (Obaid, 2016).

Obaid refers to a set of characteristics for a successful mathematics teacher, including being a thinker, mastering the subject matter, being objective and educated, being able to relate mathematics to the areas of contemporary life, and being able to use technology in a way that facilitates the students' learning. Mathematics is one of the most important basic scientific subjects; it is known as the key to science, so that its use extends to subjects that were believed to have nothing to do with mathematics, such as languages, social and educational sciences, and literature.

Due to the world's tremendous development in all fields, and in so many different fields, the different branches of knowledge have overlapped; and they have now become interrelated and inseparable from each other. Therefore, the development of mathematics education has become an interdisciplinary subject, a necessity imposed by the characteristics of this era, in order to raise the level of mathematics education (Al-Saeed and Al-Gharqi, 2015). 
The status of teaching mathematics is linked to a set of mental perceptions of the teaching profession in terms of strategic teaching practices and their impact on the educational process, and on the evaluation of educational outputs. The recent directions in evaluating teachers' performance focus on the link between evaluating students' performance and the status of teaching mathematics to the teacher in the light of the student's acquisition of the knowledge that affects the building of his personality (Shakman et al., 2012).

Education has changed, because of the Corona pandemic; many countries have simply closed their schools, including that which our country has done; since the first citizen was infected with the Coronavirus on the twelfth of March 2021.

Teaching was suspended on the 14th of Rajab of the same year; and it relied on the virtual school (the unified educational system) and on the Ain TV channels. At the beginning of the next school year, the royal order was issued to continue using remote education through the virtual school (my school platform) and via the Ain TV channels.

\subsection{The Research Problem}

The Ministry of Education in the Kingdom of Saudi Arabia has made distinct and continuous efforts during the academic year of $1441 \mathrm{AH}$, to support electronic education financially and technically under the circumstances of the Covid 19 pandemic, through its provision of the Madrasati platform and the television channels. It has also provided many training courses for teachers to deal with elearning, in a manner that reflects positively on students' educational levels and on their abilities.

In addition to many studies that have been conducted on the effectiveness of hypothetical classes, including those of Bodie, (2009); Lu, (2011); Riegel \& Kozen, (2016); Shuaib, (2016); AL-Saeed and AL-Abed, (2018); AL-Omari and Ismail, (2019) and also that which was recommended by Khalil's study (2021) for conducting evaluation studies on the current status of mathematics.

In addition to that which is mentioned above and given the field experience of the researchers and what they have observed of the possibilities for their colleagues to use virtual classes in teaching mathematics, the current study focuses on identifying the status of teaching mathematics in virtual classes during the Covid 19 pandemic. It then recognizes the level of teaching practices of mathematics teachers in simultaneous virtual classes, and the differences in these practices that might be attributed to gender, academic qualifications, and the number of years of teaching experience.

The current study has aimed to answer the following questions:

1st. What is the level of the teaching practices of mathematics teachers in simultaneous virtual classes during the Covid-19 pandemic from the teachers' point of view?

2nd. Are there statistically significant differences in the significance level ( $\alpha \leq$ 0.05 ) as regards the teaching practices of mathematics teachers in 
simultaneous virtual classes during Covid-19, due to gender, academic qualification, and the number of years of experience?

\subsection{The significance of the study}

The importance of the study resides in two aspects:

- The theoretical importance: the current study may contribute to the cumulative knowledge of the teaching performance of mathematics teachers in the light of the teaching trends in virtual classes, in addition to motivating the researchers in the field of the curriculum and the methods of teaching mathematics, in order to conduct more research and studies under the conditions of the Covid 19 pandemic, and according to the researchers' knowledge; since local and Arabic studies are still very few in this field.

- The applied importance: it is expected that the current study will be beneficial for the following categories:

1. Mathematics teachers in terms of using teaching applications and practices, in order to implement the teaching approach in virtual classes.

2. Providing experts and specialists with the standards of the status of mathematics teaching, according to the teaching approach in virtual classes, in order to benefit from them, when developing curricula suitable for the teaching practices.

3. It is useful for educators, specifically those responsible for curriculum development, to prepare mathematics teachers during their service, in coordination with the Faculties of Education in training, and according to the teaching approach in virtual classes.

4. The results of this study could be beneficial for those responsible for the professional development programs for mathematics teachers, in order to evaluate teaching, according to the teaching approach used in the virtual classes.

\subsection{The definition of the terms}

1.3.1 The status of mathematics teaching

Abdel Wahab (2007) defines this as a set of behaviours and practices that the teacher performs, in order to motivate the learners' imagination and to encourage them to search, discover, and deal with the data and information, as well as to achieve the limited educational goals.

It is procedurally defined here as the set of behaviours and procedures that mathematics male and female teachers intentionally carry out, and in planning to achieve the desired educational goals in simultaneous virtual classes.

\subsubsection{Simultaneous virtual classes}

Khleif (2009) defines such classes as one of the main methods for evaluating direct lessons and lectures on the Internet, which have the basic elements that every teacher and student needs; and this depends on the interactive teaching method. They are called smart classes and electronic classes. 
They are procedurally defined here as advanced technical means provided by the Ministry of Education in the Kingdom of Saudi Arabia in cooperation with Microsoft, in the name of Microsoft Teams, for the use of mathematics teachers, in order to provide the necessary learning elements that students need in public schools to achieve their learning goals.

\subsubsection{The Covid 19 pandemic}

The World Health Organization (2020) defines COVID-19 as a disease caused by the evolving Corona virus. The organization discovered this emerging virus for the first time on December 31st, 2019, after a number of viral pneumonia cases were reported in Wuhan in the Republic of China.

\section{The Literature Review}

Several studies have been conducted on education, in the light of the Corona pandemic (Covid-19). Since it is necessary to define the concept, the literature review starts by describing the nature of virtual mathematics education and then studying thecause and effects of virtual mathematics education; it then provides the findings of the currentstudy on virtual matheamtics education .

\subsection{The description or nature of virtual mathematics education}

Adnan and Anwar (2020) aimed to know the attitudes of Pakistani higher education students towards online education in the light of the Corona pandemic. The study concluded that online education cannot achieve its goals in poor countries, the population of which have difficulty in accessing the Internet, due to technical and financial problems, as is the case in Pakistan. The study of O'Keefe et al. (2020) was conducted in cooperation with the Organization for Economic Cooperation and Development (OECD) with Harvard University.

The study aimed to document and study the status of e-learning in public education in the light of the Corona pandemic. The study also tried to come up with initiatives to develop and improve its practices in the Kingdom, according to the latest global practices and standards related to this field. The results of comparing the responses of the Kingdom of Saudi Arabia to education during the Corona pandemic within 37 member states have showed that the Kingdom of Saudi Arabia is advanced, in 13 indicators out of 16, on the average of these countries; and it revealed that teachers have received significant support, in order to overcome the obstacles in activating e-learning.

Hassan's study (2020), which dealt with teaching and learning mathematics remotely in the light of the Corona pandemic, recommended the necessity of identifying the appropriate electronic and interactive software for each school stage, and for training teachers therein. Khamisi's study (2020) aimed to bridge the gap between home and school; and it recommended some requirements to achieve this, the most important of which were: increasing political and financial support for the Ministry of Education in its initiatives, its digital transformation, and in distance education, and legislating the regulations that are compatible therewith in regard to the organization of the study procedures, the timetable, and the evaluation methods. 
As for Khalil's study (2021), it presented a suggested teaching model in the light of the trend of the mathematical ability to teach mathematics in simultaneous virtual classes; and it recommended conducting evaluation studies, in order to teach mathematics under the current circumstances.

To continue the educational process, and in the light of the technological development in the world, e-learning has been relied on. E-learning is defined by Al-Astal and Al-Farra (2013), as education by using computers and their various programs, whether on closed or shared networks, or on the global Internet. Mubariz and Fakhri (2013) have defined this as an education that allows individuals to learn at any time they choose, wherever they are, in any medium (personal computer, the Internet,) and with a learning speed that suits their personal abilities.

It is based on the principles of Brunner's theory of learning, in terms of observing the characteristics of the learners, thereby providing a great deal of freedom in learning situations, taking into account individual differences between the learners, being centered around the learners, and relying on their activities (Kotait, 2015).

It also provides different styles of interaction between learners, most notably the simultaneous virtual classroom, which is known as an online environment that allows students and teachers to communicate simultaneously, by using audio and video, text chat, interactive whiteboard, application sharing, instant polling, etc. (Martin et al., 2013).

Kotait (2015) defines a simultaneous virtual classroom as "the interaction of students with one another and with the teacher at the same time, but in different places, and at great distances across the network." It can also be defined as a virtual environment that brings the teacher and the learner together at the same time, regardless of where they are, in order to achieve specific learning objectives.

\subsection{Studying the cause and effect of virtual mathematics education}

The simultaneous virtual classroom is characterized by the availability of many simultaneous tools, working together in an integrated framework, in order to achieve effective communication between the students and their teacher, through the various tools of communication with a large amount of interaction between them and the curriculum, and with the ability to provide continuous reinforcement and feedback.

However, there are some technical difficulties facing mathematics teachers; the most prominent of which are: the large number of students in the classroom, the lack of a device for every student, the weakness of the Internet in some areas, and the lack of experience of teachers and students in using the various techniques (Al-Ruwais, 2011; Khalil and Al-Massad, 2016; Al-Anzi and AL-Massad, 2018; Hamada and Al-Shawahin, 2019). 
The teacher has tasks in virtual classes, such as designing educational experiences and educational activities commensurate with the learner's experiences, preferences, and interests, preparing appropriate evaluation methods for this, following up on students' attendance and academic progress, creating a comfortable learning environment for students, and defining the rules of behaviour to be followed by them, asking questions that develop students' thinking skills, and providing feedback constantly, in addition to guiding them to find additional learning resources that can be found on the network (Al-Najjar and Abu Shkir, 2014).

\subsection{The findings of the previous studies onvirtual mathematics education}

Several studies were conducted on virtual classes from several perspectives, such as that of Bodie (2009), which aimed to explore the extent to which the teacher interacts with the learners in the educational process, with the means of communication in the virtual classroom. The study of $\mathrm{Lu}$ (2011) aimed to experiment with the virtual classroom in teaching mathematics via the Internet. The results showed that the use of virtual classrooms enhances communication in teaching mathematics via the Internet, while the study of Rigel and Kozen (2016) aimed to teach and learn the skills of the twenty-first century in the virtual classroom.

The study concluded that the virtual classroom may have a lot to offer, even more than traditional classrooms in terms of acquiring and mastering the skills of the twenty-first century. Moreover, the study of Shuaib (2016) aimed to determine the most appropriate type of virtual classroom that helps in providing educational content for kindergarten female pupils.

The results found that there were statistically significant differences at the level of $a \leq 0.05$ between the mean scores of the two experimental groups (simultaneous versus asynchronous). The evaluation card of electronic educational games software was produced for the benefit of the group (simultaneous virtual classrooms).

The study of Al-Saeed and Al-Abed (2018) aimed to know the effectiveness of using virtual classes in mathematics, and of logical thinking among tenth-grade students. The study found that there are statistically significant differences at the level of significance $(\alpha \leq 0.05)$ between the mean scores of the experimental group of students and the scores of the control group of students in the post-application of the achievement and logical reasoning tests in favour of the experimental group.

As for the study of Al-Ahmari (2019), which aimed to give a presentation of the experience of the Saudi Virtual School, the results showed that it relied on concurrent classes, and that there is a positive trend for students and teachers to learn by using it, and that their satisfaction is directly affected by the level of technology used.

The study of Al-Omari and Ismail (2019) aimed to discover the effect of simultaneous virtual classes in achieving professional practices among 
mathematics teachers in the middle stage. The study concluded that there are statistically significant differences at the level of significance $(\alpha \leq 0.05)$ between the mean scores of the experimental group in the pre- and in the post-applications, to test the cognitive aspect of professional practice skills and to note the performance side-card for professional practice skills in favour of the postapplication.

The study by Elzainy et al., (2020) was conducted at the College of Medicine, Qassim University; it aimed to describe the simultaneous procedures for elearning and evaluation, and the effect of e-learning on students' performance, faculty members, and the challenges facing their sustainability. The results found that there are statistically significant differences in the average grades of students during the electronic sessions of learning, based on solving problems. In addition, there was a high level of satisfaction of the faculty members with virtual classes, e-assessment, and e-workshops.

Eddie and José (2020) tried to uncover online mathematics learning activities for teachers in the Covid-19 period (Eddie \& José, 2020). The results concluded that mathematics learning of online activities has demonstrated that students on the Internet showed excellent performance in acquiring mathematics learning skills in technology-rich settings and the availability of online platforms when compared to those groups in poor settings (Eddie \& José, 2020).

While most of the previous studies tried to study the effect of the virtual classroom on mathematics education, the current study has tried to assess the status of teaching mathematics through virtual classes in the light of the Covid 19 pandemic.

\section{The Methodology}

The descriptive approach was used to answer the study questions, and to achieve the objectives, by recognizing the status of teaching mathematics in simultaneous virtual classes in the light of the Covid 19 pandemic (Wardat et al., 2021), specifically uncovering thereby the degree of teaching practices of mathematics teachers in simultaneous virtual classes in the light of the Covid 19 pandemic from the teachers' perspectives by using questionnaires.

The descriptive approach is based on describing the phenomenon quantitatively, by giving it scores that express the degree of actual practices, in order to describe the studied phenomenon and to diagnose reality, and to reach conclusions and analyses, based on the quantitative results that contribute to understanding and diagnosing the status of these results (Obaidat, Adas \& Abdelhak, 2011).

\subsection{The population}

The population of the study consisted of all mathematics, male and female teachers, in all stages of education in the Qassim region in government schools. 


\subsection{The Sample}

The sample of the study consisted of 385 male and female teachers, who were selected randomly. It consisted of 283 male teachers and 102 female teachers from the entire population. Table 1 shows the characteristics of the sample of the study, according to the variables of gender, academic qualification, and the number of years of experience in teaching:

Table 1. Distribution of the sample of the study, according to the variables

\begin{tabular}{llll}
\hline Variable & Type & Number & Percentage $\%$ \\
\hline \multirow{2}{*}{ Gender } & Male & 283 & $73.5 \%$ \\
& Female & 102 & $26.5 \%$ \\
Qualification & Bachelors & 326 & $84.7 \%$ \\
& Higher studies & 59 & $15.3 \%$ \\
Teaching & Less than 5 years & 45 & $11.7 \%$ \\
experience & From (5-10) & 142 & $36.9 \%$ \\
& More than 10 & 198 & $1.4 \%$ \\
\hline
\end{tabular}

As shown in Table 1 above, the number of the sample of the study comprises 385 in total. The number of males was 283 teachers, representing $73.5 \%$, while the number of females was 102 , thereby presenting $26.5 \%$ of the sample members. Those participants with a Bachelor's degree were 326, representing $84.7 \%$ of the whole sample; and the number of participants with degrees higher than the Bachelors amounted to 59 , representing $15.3 \%$.

Concerning the teaching-experience variable, the number of participants whose service was less than 5 years amounted to 45 , representing $11.7 \%$ of the sample. The number of participants with experience of 5-10 years reached 142 participants, representing 36.9\%; while the number of participants with more than 10 years of experience reached 198 participants, representing $51.4 \%$.

\subsection{The study tool}

The questionnaire was used as a tool to collect the data. The following steps were followed to build the questionnaire:

The authors identified the teaching practices for mathematics teachers that were measured in virtual classes. Many previous studies that related to the status of teaching mathematics in virtual classes were analyzed, such as those of Adnan and Anwar (2020), Hassan (2020), Al-Khamisi (2020), Lu's (20,11), Shuaib (2016), and AL-Ahmari (2019).

The questionnaire consisted of 29, items distributed in the following fields and dimensions: 1) Teaching planning: this measures the teacher's performance and behaviour at the beginning of the lesson. It includes the introduction, the activities, the identities, the introductory questions, the projects, and the problems, according to that which was planned, and which the teacher poses to the students at the beginning of the session, in order to question the students, and to link the knowledge and any previous experiences of the students to the topic of the lesson. 
This field consisted of 6 paragraphs, with serial numbers from 1-6;

2) Teaching new mathematical knowledge: this measures the teacher's performance behaviour during the lesson. It includes positive mathematical culture in the classroom; the teaching methods and the strategies used that consisted of 12 paragraphs with serial numbers from 7-18.

3) Classroom management and raising the level of interaction: this measures the teacher's performance behaviour during the implementation of the lesson, by way of the class interaction, the distribution of activities, time, class management, the participation of the students in determining the course of the lesson, and the diversification of the methods of receiving students' responses to activities (chatting - WhatsApp --... etc.), allowing mathematical dialogue among the students, and using electronic participatory learning strategies in building and organizing the work of cooperative learning groups. This field consisted of 5 paragraphs that took serial numbers from 19-23.

4) Evaluation: this measures the teacher's performance behaviour during and at the end of the lesson. It includes the evaluation methods and the strategies used, based on realistic evaluation, constructive and final evaluation, self-evaluation, and the questions that the teacher asks to implement the survey. This field consisted of 6 paragraphs that took the serial numbers from 24-29.

All the paragraphs of the fields were written positively. The response to the paragraphs was graded by following the five-point grading of the Likert method (very high, high, medium, low, very low). The open-class method was followed, in order to determine the criteria for evaluating the degree of teaching practices of mathematics teachers in simultaneous virtual classes, in the light of the Covid 19 pandemic in the questionnaire.

All the paragraphs of the fields were written positively. A high score indicates a high degree of the measured characteristic "practices." A low score indicates a low score, according to Likert's five-point grading (Likert); and it reveals the status of mathematics teaching. The range of response levels was calculated; and it was = 4. By dividing the range by the number of levels of estimating the degree of teaching practice, which is equal to 5 , the result of the division $=0.80$, which represents the length of the category. Thus, the criterion for evaluating practices became as clear as that used in Table 2:

Table 2. The criterion for evaluating the status of teaching mathematics in simultaneous virtual classes in the light of the Covid-19 pandemic

\begin{tabular}{lll}
\hline Interval & Responses & Mathematics teaching \\
\hline From 1-less than 1.80 & Very low & Very low \\
From 1.80-less than 2.60 & low & low \\
From 2.60-less than 3.40 & Medium & Medium \\
From 3.40-less than 4.20 & High & High \\
From 4.20-5.00 & Very high & Very high \\
\hline
\end{tabular}




\subsection{The validity of the questionnaire}

To verify the validity of the questionnaire's content, and to ensure that it achieves the objectives of the study, it was presented in its initial form to a group of 11 experts and supervisors, experienced and specialized referees from the teaching staff in Saudi universities and educational supervisors, in order to benefit from their observations and experiences, intending to judge the questionnaire to ensure that the indicators of the questionnaire were all included and covered in the areas of measuring the status of teaching mathematics; and to ensure the integrity, clarity, and non-repetition of the linguistic formulation.

In the light of the directives given by the referees, linguistic amendments and reformulation were carried out. The percentage of the original paragraphs that achieved an agreement between the referees was $80 \%$ or more, belonging to the measured field; and the appropriate linguistic adjustments were then made.

The validity of the internal consistency of the paragraphs was carried out by applying the questionnaire to a pilot sample from outside the study sample, and by calculating the correlation coefficients of the degree of each paragraph with the total degree of the field, to which the paragraph belonged. All the values of the correlation coefficients came to acceptable values, as they ranged between $0.392-0.866$.

In the light of these results, the internal consistency of the paragraphs of the questionnaire were validated, according to its consistency in the field. The validity of the internal consistency of the fields of the questionnaire was verified, in order to evaluate the status of teaching mathematics as well. Its correlation coefficients ranged between 0.89-0.93, a matter which indicates the consistency of the field in the questionnaire; this indicates the validity of the construction of the questionnaire, which are all statistically significant at the level of significance (0.05).

\subsection{The reliability of the questionnaire}

Checking the reliability of the questionnaire was carried out by calculating the degree of reliability of each field of the questionnaire, by applying to the pilot sample from outside the original study sample, by using the method of internal homogeneity reliability, and by applying the Cronbach Alpha method, where the total reached 0.94; while the reliability coefficient of the fields ranged between $0.74-0.92$. The questionnaire proved to be reliable; and it may be applied to the primary sample in the light of these results.

\subsection{The data analysis}

The data were analyzed by using the mean, the standard deviation, $t$-test, the significance levels, and the one-way analysis of the variance (another VA), employing SPSS version 22. We used the mean and the standard deviation to calculate the value given by the study sample to each paragraph, as well as the general arithmetic mean for each field. We used $t$-tests to check the difference between the averages of two independent samples, in order to find the differences between the averages of the estimation of the status of teaching Mathematics attributed to academic qualification and gender, and the one-way analysis of the 
variance (ANOVA), in order to detect any differences, according to the number of years of experience variable (Stoica \& Wardat, 2021).

\section{The results}

4.1 The results of the first question: What are mathematics teachers' level of teaching practices in simultaneous virtual classes during Covid- 19 from the teachers' perspective? To answer this question, the general mean was calculated for each domain; and it has been arranged in descending order, according to the mean, as the results show in Table 3.

Table 3. The level of teaching practices of mathematics teachers in simultaneous virtual classes during Covid-19 from the teachers' point-of view

\begin{tabular}{llllll}
\hline Sr. & Field & Mean & SD & Level & Rank \\
\hline 1 & Teaching planning & 3.87 & 0.75 & High & 1 \\
2 & Teaching new mathematic & 3.81 & 0.66 & High & 2 \\
& knowledge & & & & \\
4 & Evaluation & 3.80 & 0.69 & High & 3 \\
3 & $\begin{array}{l}\text { Class management and the rising } \\
\text { interaction level }\end{array}$ & 3.67 & 0.83 & High & 4 \\
\hline Total & $\mathbf{3 . 8 0}$ & $\mathbf{0 . 6 2}$ & High & \\
\hline
\end{tabular}

It is clear from the previous table that the overall mean grades of teaching practices evaluation in simultaneous virtual classes of mathematics male and female teachers from the point of view of the teachers amounted to $3.80 / 5$, which is a high degree and with a standard deviation of 0.62 , indicating the agreement of the grades. The high degree of male and female teachers might be attributed to the technological competencies to plan, implement and evaluate the lesson in the virtual classroom because of the courses they had previously attended, the fact that the developed curricula helped them to apply this type of e-learning, the presence of the AL-AIN platform that supports the professional development of mathematics male and female teachers, and for the cooperation of all school elements, school leaders, teachers, and students.

The skills that measure the status of teaching in the field of planning came in the first rank, with a high degree, with a mean value of 3.87 / 5 and with a standard deviation of 0.75 . The results indicate the similarity of the evaluation of practices from the viewpoint of the study members in this field. The reason for their appearance in the first rank is due to planning the lesson, in which the subject of the lesson and the previous learning could be linked to the students' previous experiences related to the lesson and the linkage with practical life situations.

The reason for the emergence of the results is related to planning with practical reality; this is highly justified by the fact that the teacher links the students' previous experiences related to the concepts of the lesson as an entry point to prepare for teaching practices. The field of "teaching new mathematical knowledge" came in the second rank, and also with a high degree; the value of its mean was 3.81, with a standard deviation of 0.66 , thereby indicating the agreement of the estimates. The field of evaluation came in the third rank with a 
mean of 3.80 with a high degree and with a standard deviation of 0.69 , indicating thereby the agreement of the estimates.

This may be explained by the fact that mathematics male and female teachers possess the skills related to the electronic evaluation required for teaching in virtual classes when teaching mathematics, such as using the electronicachievement file and sending assignments and homework projects through the electronic platform.

While the level of teaching practices in simultaneous virtual classes came in the last rank in the field of classroom management, by raising the level of interaction to a high degree; the value of its mean was 3.67 , with a standard deviation of 0.83 , thereby indicating the agreement of the estimates. The reason for the emergence of the field in the last rank might be attributed to the fact that teaching mathematics in virtual classes requires teachers with special skills in electronic interaction.

Moreover, technical and skill factors related to students and the conditions of the state of communication between the teacher and the students may affect the outcome; but its appearance in a high degree might be related to the participation of students in determining the course of the lesson, the ability of teachers to diversify the methods of receiving students' responses to activities (chatting WhatsApp --... etc.), the potential provided by the platform in terms of providing an opportunity for mathematical dialogue between students, and the use of electronic-participatory learning strategies in building and organizing the work of cooperative learning groups.

For more details in answering the first question, the mean and the standard deviation were calculated for all the paragraphs of each field. They were also arranged, according to the mean, in descending order. In the case of equal means, they were arranged, according to the value of the lowest standard deviation, as follows:

\section{The first field: Lesson-planning skills}

Table 4. The level of teaching practices of mathematics teachers in the field of lessonplanning

\begin{tabular}{llcccc}
\hline Sr. & Paragraph & Mean & SD & Sequence & Level \\
\hline 1 & 3.96 & 0.92 & 3 & High \\
& $\begin{array}{l}\text { Identify the applications and the } \\
\text { programs appropriate to the topic of the } \\
\text { lesson. }\end{array}$ \\
2 & 3.92 & 0.94 & 4 & High \\
$\begin{array}{l}\text { Specify previous experiences related to } \\
\text { the lesson to compensate for the } \\
\text { educational losses. }\end{array}$ & 3.22 & 1.24 & 6 & Middle \\
$\begin{array}{l}\text { Design (visual diagrams - videos ...) } \\
\text { around the most prominent ideas of the } \\
\text { lesson. }\end{array}$ & & & & 5 & High \\
& $\begin{array}{l}\text { Discuss with my fellow teachers the } \\
\text { proper way to communicate mathematical } \\
\text { ideas in the Virtual Classroom. }\end{array}$
\end{tabular}


Take into account the distribution of class time, to ensure that the lesson is presented in an integrated manner.

6 Use the internet to get references, enrichments, and various lesson formats.
4.25

0.87

0.93

3.78
1

Very

High

Very

High

High

It is evident from the results of Table 4 that the general mean of the grades of the study members of mathematics male and female teachers of the practices of teaching mathematics in simultaneous virtual classes in the light of the Covid-19 pandemic in the field of lesson planning, was of a high degree; where the value of the mean was 3.87 with a standard deviation of 0.75 , thereby indicating the agreement of the estimates of practices; and the values of the standard deviations of the paragraphs that ranged from $0.87-1.35$. These values indicate the agreement of the estimates of the practices.

Through the results of the arrangement of the paragraphs that measure the teaching practices in the field of planning the lesson, two paragraphs came to a very high degree; the paragraph "Take into account the distribution of class time to ensure that the lesson is presented in an integrated manner", was in the first rank with a mean value that reached 4.25 .

The reason for this result is that the nature of teaching in virtual classes is related to a time program; and the teacher tries to manage the class time and to overcome communication problems, as well as technical communication problems, as a result of emergency malfunctions or defects in the network.

The teacher is keen to invest the time of learning and teaching by taking advantage of the technical features provided by distance education in a planned way, and by enriching the share with interactive exercises. The paragraph "Use the Internet to obtain references, enrichment and different models for the lesson" came in the second rank, with a very high degree in terms of practice. Its mean (4.22) and the standard deviation (0.93), as the educational platform, contributed through the ease of linking the lesson to the rich activities via the Internet.

As for the paragraphs: "Identify the appropriate applications and programs for the subject of the lesson" and "Specify the previous experiences related to the lesson, in order to compensate for the educational loss"; and "discuss with your classmates the appropriate method for communicating mathematical ideas in the virtual classroom".

They came with high degrees of practice. The values of their means ranged from 3.52-3.96. It was noted that the value of the standard deviation for the paragraph: "I discuss with my fellow teachers the appropriate method for communicating mathematical ideas in the virtual classroom." This amounted to 1.35, thereby indicating the existence of a large difference and variation in its practice and possible differences in the interests of male and female teachers, as well as the conditions related to teachers' professional development activities, which may have contributed to the existence of variations in practice. 
For the paragraph: "Design visual diagrams - video clips ... about the most prominent ideas of the lesson", this came into the last rank, with a middling degree, and with a mean of 3.32, together with a large standard deviation of 1.24, thereby indicating the different levels in its practice. The reason for this may be explained by the lack of interest in applying this approach to elementary school students; and perhaps because teachers lack the skills to design visual diagrams video clips ... about the most prominent ideas of the lesson for the adoption of the majority of male and female teachers on the electronic content in the educational platform, a matter which requires training teachers to employ electronic mental maps and to be prepared for the preparation and design of an interactive video, in order to display the lessons' ideas.

\section{The second field: Teaching the new mathematical knowledge}

Table 5. The level of teaching the practices of mathematics' teachers in the field of teaching new mathematical knowledge

\begin{tabular}{|c|c|c|c|c|c|}
\hline $\mathrm{Sr}$ & Paragraph & Mean & SD & Sequence & Level \\
\hline 7 & $\begin{array}{l}\text { I take into account the time spent using } \\
\text { in-class technology. }\end{array}$ & 4.15 & 0.79 & 2 & High \\
\hline 8 & $\begin{array}{l}\text { I use visual presentations and } \\
\text { multimedia programs to explain the } \\
\text { lesson. }\end{array}$ & 3.89 & 1.06 & 7 & High \\
\hline 9 & $\begin{array}{l}\text { I link new mathematical experiences with } \\
\text { previous experiences, in order to } \\
\text { compensate for educational losses. }\end{array}$ & 4.14 & 0.88 & 3 & High \\
\hline 10 & $\begin{array}{l}\text { I relate the different lesson ideas to one } \\
\text { another. }\end{array}$ & 4.38 & 0.72 & 1 & $\begin{array}{l}\text { Very } \\
\text { High }\end{array}$ \\
\hline 11 & $\begin{array}{l}\text { I refer to the relationship of the lesson to } \\
\text { the possible applications in life. }\end{array}$ & 4.10 & 0.85 & 4 & High \\
\hline 12 & $\begin{array}{l}\text { I balance the conceptual and procedural } \\
\text { knowledge of the lesson. }\end{array}$ & 3.99 & 0.76 & 5 & High \\
\hline 13 & $\begin{array}{l}\text { I use virtual engineering tools, while } \\
\text { solving mathematical problems. }\end{array}$ & 3.61 & 1.09 & 10 & High \\
\hline 14 & $\begin{array}{l}\text { I use electronic mathematical activities in } \\
\text { the presentation of the lesson. }\end{array}$ & 3.63 & 1.02 & 9 & High \\
\hline 15 & $\begin{array}{l}\text { I use electronic communication } \\
\text { applications to provide reinforcement } \\
\text { and feedback to the students. }\end{array}$ & 3.79 & 1.19 & 8 & High \\
\hline 16 & $\begin{array}{l}\text { I use 3D models to display mathematical } \\
\text { shapes and symbols. }\end{array}$ & 3.24 & 1.12 & 11 & Middle \\
\hline 17 & $\begin{array}{l}\text { I employ electronic games to develop } \\
\text { various mathematical skills. }\end{array}$ & 2.89 & 1.21 & 12 & Middle \\
\hline 18 & $\begin{array}{l}\text { I use a variety of teaching methods and } \\
\text { strategies. }\end{array}$ & 3.94 & 0.83 & 6 & High \\
\hline \multicolumn{2}{|c|}{ Total } & 3.81 & 0.66 & & High \\
\hline
\end{tabular}

The results of Table 5 show that the general mean of the practices of teaching mathematics in virtual classes in the field of teaching new mathematical knowledge was of a high degree. The value of the mean was 3.81 , with a standard 
deviation of 0.66 , thereby indicating the agreement of the estimates in practice; and the values of the standard deviations of the paragraphs ranged from 0.72-1.21. Most of these values indicate the agreement of the estimates of practices.

Through the results of the arrangement of the paragraphs, the paragraph "I connect between the different ideas of the lessons came in the first order, where the value of its mean was very high (4.38).

The reason for this result is that the nature of the mathematics lessons depends on each other; and it is necessary to emphasize the complementarity of the content. When presenting the electronic content of the new lesson and linking the students' previous experiences with their experiences gained from previous lessons, and linking the ideas of one lesson, it is important that a smooth transition is made to organize the ideas correctly.

Some other paragraphs came with high degrees of practice, where the means ranged from 3.61-4.15; and they are arranged respectively: "I take into account the time allocated for the use of techniques within the class and I link new mathematical experiences with the previous experiences, in order to compensate for educational losses". "I refer to the relationship of the lesson with life applications". "I balance between conceptual and procedural knowledge for the lesson". "I use various teaching methods and strategies". "I use visual presentations and multi-media programs to explain the lesson". "I use electroniccommunication applications to provide reinforcement and feedback to my students". "I employ electronic mathematical activities in presenting the lesson"; and "I use virtual engineering tools, while solving mathematical problems" that exhibit high values.

However, there is a difference between male and female teachers in four paragraphs, including the use of visual presentations and multi-media programs in explaining the lesson, the use of electronic communication applications in providing reinforcement, and in feedback to students, the use of electronic mathematical activities in the presentation of the lesson, and the use of virtual engineering tools, while solving mathematical problems. Their standard deviations ranged from 1.02-1.19, thereby indicating the difference in the degrees of practice.

This may be due to the existence of individual differences related to electronic skills in teaching new mathematical knowledge, and the different interests of male and female teachers in employing them; and some teachers may need training in them, and in developing their level of skilled knowledge therein.

As for the paragraph: "I use 3D models in displaying mathematical figures and symbols," it came in the next-to-last rank, with a mean score of 3.24, and with a large standard deviation of 1.12. This indicates the difference in the level of practice. The reason for this may be explained by the lack of some teachers possessing the related skills in mathematical modelling. Consequently, 3D models are used to display mathematical shapes and symbols, a matter which requires 
sufficient training and experience for the teacher in the field of information technology and educational techniques.

As for the paragraph: "I employ electronic games to develop various mathematical skills", it came into the last rank, with a medium degree and with a mean of 2.89 , and with a large standard deviation of 1.21. This indicates the difference in the levels of practice. The reason behind this may be explained by the lack of some teachers possessing the skills to employ electronic games and to develop mathematical skills, the lack of teachers' knowledge of the methods of manipulation in teaching, and the lack of programs that support the employment of educational games in teaching, a matter which requires the development of teachers' skills in this aspect.

The third field: Classroom management and raising the level of interaction

Table 6 . The level of teaching practices of mathematics teachers in the field of classroom management and raising the level of interaction

\begin{tabular}{llllcc}
\hline Sr. & Paragraph & Mean & SD & Sequence & Level \\
\hline 19 & $\begin{array}{l}\text { I share the responsibility of setting the } \\
\text { course of the lesson with the students. }\end{array}$ & 4.03 & 0.91 & 1 & High \\
20 & $\begin{array}{l}\text { I vary the ways to receive students' } \\
\text { answers to activities (chatting - }\end{array}$ & 3.75 & 1.25 & 2 & High \\
$\begin{array}{l}\text { WhatsApp - .. etc.) } \\
\text { I allow a mathematical dialogue } \\
\text { between the students. }\end{array}$ & 3.78 & 1.05 & 3 & High \\
$22 \quad 3$ I use the e-participatory learning \\
$\begin{array}{l}\text { strategies in building and organizing } \\
\text { the work of the collaborative learning } \\
\text { groups. }\end{array}$
\end{tabular}

The results of Table 6 show that the general mean of the scores for teaching mathematics practices in virtual classes in the field of classroom management and thereby raising the level of interaction, is high. Where the value of the mean was 3.67 , the standard deviation was 0.83 , thereby indicating the agreement between the estimates of practices.

The paragraph: "I shared the responsibility in setting the course of the lesson with the students, who came in the first rank, where the mean was 4.03. The reason for this result is the awareness of mathematics male and female teachers on the importance of taking into account the interactive element in implementing virtual classroom lessons and motivating students to participate by adopting learning methods and considering the learners' styles. Then, most of the other paragraphs came with high scores; and their means ranged from 3.46-3.78. They are ordered respectively, as follows: "I allow a mathematical dialogue between the students; "I vary the ways to receive students' answers to activities (chatting - WhatsApp ... etc.)"; and "I use the e-participatory learning strategies in building and organizing the work of the collaborative-learning groups." 
As for the paragraph: "I use electronic means to communicate with parents". This came in the last rank with a medium degree and a mean of 3.34 and with a large standard deviation of 1.26. The reason for this may be attributed to the lack of communication with the students' parents on the increase of their work duties related to preparing for the lesson and the lack of time in their program, a matter which may not contribute to allowing the teacher to communicate with the parents of students, especially since the quorum is large for most teachers; and there are usually a large number of students in the virtual classes.

\section{The fourth field: Evaluation}

Table 7. The level of teaching practices of mathematics' teachers in the field of evaluation

\begin{tabular}{|c|c|c|c|c|c|}
\hline Sr. & Paragraph & Mean & SD & Sequence & Level \\
\hline 24 & $\begin{array}{l}\text { I use electronic tests to assess } \\
\text { students' levels. }\end{array}$ & 4.28 & 0.87 & 1 & $\begin{array}{l}\text { Very } \\
\text { High }\end{array}$ \\
\hline 25 & $\begin{array}{l}\text { I keep electronic achievement files } \\
\text { for each student. }\end{array}$ & 3.42 & 1.12 & 5 & High \\
\hline 26 & $\begin{array}{l}\text { I direct students to perform tasks } \\
\text { with a variety of ideas. }\end{array}$ & 3.57 & 1.01 & 4 & High \\
\hline 27 & $\begin{array}{l}\text { I vary in evaluation paragraphs } \\
\text { (multiple choice - true and false ...). }\end{array}$ & 4.18 & 0.95 & 2 & High \\
\hline 8 & $\begin{array}{l}\text { I direct students to make reflective } \\
\text { summaries to relate their lesson } \\
\text { ideas. }\end{array}$ & 3.21 & 1.14 & 6 & Middle \\
\hline 29 & I provide feedback after evaluation. & 4.04 & 0.93 & 3 & High \\
\hline Total & & 3.80 & 0.69 & & High \\
\hline
\end{tabular}

As shown in the results of Table 7, the general mean of the grades of the assessment of the level of mathematics teaching practices in the virtual classes in the field of the evaluation, was high. Where the value of its mean (3.80) was very high, with a standard deviation (0.69), thereby indicating the agreement of the estimates of practices, the values of the standard deviations of the paragraphs ranged from 0.87-1.14. The emergence of practices was related to their evaluation to a high degree, due to the presence of high competencies among mathematics teachers in using electronic tests to assess the level of their students, as well as their ability to diversify questions, and to provide feedback and to make achievement files.

Through the results of the ranking of the paragraphs that measure the teaching practices in the field of evaluation, the paragraph "I use electronic tests to evaluate the level of students" came first; since its mean value reached 4.38. The reason for this result is related to the digital platform and communication forums between the teachers, which provided opportunities for the improvement and the development of the professional performance of mathematics - both male and female teachers, in the field of building electronic tests. 
Most of the other paragraphs came with high scores. Their means ranged from 3.42-4.18; and they are arranged in order: "I vary in the evaluation paragraphs (multiple choice - true and false...)"; "I provide feedback after evaluation"; and "I instruct students to tackle performance tasks with ideas". It was noticed that there is a difference in the practices of male and female teachers in directing their students to conduct performance tasks with various ideas; and to keep the electronic files of achievement for each student. The values of their two standard deviations, respectively, $(1.01,1.12)$ indicate the different levels of practice. This is due to the difference in the skill levels; since not all mathematics teachers can provide various tasks for the evaluation or for the design of electronic files of achievement (electronic portfolios) due to the difference in the level of teachers' ability to master the skills associated with such.

The paragraph: "I ask students to make reflective summaries to link the ideas of the lesson", came in the last rank, with a medium degree, and with a mean of 0.21 , together with a large standard deviation of 1.14, thereby indicating the difference in the estimates. The reason for this may be explained by the lack of sufficient time to implement such tasks. Perhaps the lack of support for the implementation of this practice is due to the lack of consideration for making summaries to link the lesson ideas with the educational platform.

4.2 The results of answering the second question: Are there statistically significant differences at the significance level $(\alpha \leq 0.05)$ in the level of the teaching practices of mathematics' teachers in simultaneous virtual classes during Covid19 , due to gender, academic qualification, and the number of years of experience? Two independent samples (Independent sample t-tests) were used to reveal the significance of differences attributed to gender and academic qualification; while the one-way analysis of variance (ANOVA) was used to reveal the significant differences attributed to experience, as follows:

\section{A. Gender}

To reveal the statistically significant differences in the degree of estimating the status of mathematics teaching in simultaneous virtual classes in the light of the Covid 19 pandemic attributed to gender, the T test was used for two independent samples; and the results are shown in Table 8.

Table 8. The difference between the means of the male teachers and the females on the teaching practices in simultaneous virtual classes during Covid-19

\begin{tabular}{lllllll}
\hline Field & Gender & $\mathrm{N}$ & Mean & $\mathrm{SD}$ & $\mathrm{t}$-value & $\mathrm{p}$-value \\
\hline Teaching planning & Male & 283 & 3.83 & 0.76 & -1.743 & 0.082 \\
& Female & 102 & 3.98 & 0.73 & & \\
Teaching new & Male & 283 & 3.77 & 0.65 & -1.950 & 0.052 \\
mathematic knowledge & Female & 102 & 3.92 & 0.67 & & \\
Class management and & Male & 283 & 3.63 & 0.87 & -1.891 & 0.059 \\
raising interaction level & Female & 102 & 3.81 & 0.70 & & \\
Evaluation & Male & 283 & 3.76 & 0.68 & -2.167 & 0.031 \\
& Female & 102 & 3.93 & 0.70 & & \\
Total & Male & 283 & 3.75 & 0.62 & -2.222 & 0.027 \\
& Female & 102 & 3.91 & 0.62 & & \\
\hline
\end{tabular}


Table 8 shows that there are statistically significant differences on the level of significance $(\alpha \leq 0.05)$ between the averages of estimating teaching practices in simultaneous virtual classes for mathematics teachers, due to the gender variable; as the value of $\mathrm{T}$ on the total score was -2.222; and its statistical significance was less than the level of significance (0.05).

This indicates the existence of differences in the evaluation of teaching practices in the simultaneous virtual classes of mathematics male and female teachers. These may be attributed to gender; and it was in favour of the female teachers. There were also differences in the evaluation field, where the value of $\mathrm{T}(-2.167)$ was less than the level of significance (0.05). The differences were in favour of the females. This may be explained by the fact that female teachers show a higher interest in documenting evaluation procedures in virtual classes due to the high competitiveness of female students. This leads directly to interest in the evidence of evaluation.

\section{(B) Academic Qualification}

To reveal the statistically significant differences in the degrees of estimating the status of teaching mathematics in simultaneous virtual classes in the light of the Covid 19 pandemic, which is attributed to (academic qualification), the T test was used for two independent samples; and the results are shown in Table 9.

Table 9. The difference between the means of the teachers on the teaching practices in simultaneous virtual classes during Covid-19, according to their academic qualification

\begin{tabular}{lllllll}
\hline Field & $\begin{array}{l}\text { Academic } \\
\text { Qualification }\end{array}$ & $\mathbf{N}$ & Mean & SD & $\begin{array}{l}\mathbf{t}- \\
\text { value }\end{array}$ & $\begin{array}{l}\text { p- } \\
\text { value }\end{array}$ \\
\hline Teaching planning & BA & 326 & 3.89 & 0.79 & 1.771 & 0.077 \\
& Higher than & 59 & 3.71 & 0.48 & & \\
& BA & & & & & \\
Teaching new & BA & 326 & 3.82 & 0.68 & 0.701 & 0.484 \\
mathematical & Higher than & 59 & 3.76 & 0.48 & & \\
knowledge & BA & & & & & \\
$\begin{array}{l}\text { Class management } \\
\text { and raising the } \\
\text { interaction level }\end{array}$ & BA & 326 & 3.76 & 0.85 & 0.021 & 0.983 \\
Evaluation & Higher than & 59 & 3.76 & 0.71 & & \\
& BA & 326 & 3.84 & 0.70 & 2.776 & 0.006 \\
& Higher than & 59 & 3.57 & 0.58 & & \\
\hline Total & BA & & & & & \\
& BA & $\mathbf{3 2 6}$ & $\mathbf{3 . 8 2}$ & $\mathbf{0 . 6 5}$ & $\mathbf{1 . 3 8 5}$ & $\mathbf{0 . 1 6 7}$ \\
& Higher than & $\mathbf{5 9}$ & $\mathbf{3 . 6 9}$ & $\mathbf{0 . 4 0}$ & & \\
\hline BA & & & & & \\
\hline
\end{tabular}

It is evident from Table 9 that there are no statistically significant differences in the levels of significance $(a \leq 0.05)$ between the averages of estimating teaching practices in simultaneous virtual classes for mathematics teachers due to the academic qualification variable. The value of $(t)$ on the overall degree was (1.385) and its statistical significance exceeds the level of significance (0.05), a matter which indicates that there are no differences in the evaluation of teaching practices in simultaneous virtual classes for mathematics teachers, which could be 
attributed to scientific qualification. This result is attributed to the similar perception of mathematics teachers in evaluating teaching practices in simultaneous virtual classes of mathematics; since they are similar in their use of teaching strategies, which appeared to be high, as evidenced by the results of Table 9 that there are no statistically significant differences in the level of significance $(a \leq 0.05)$ in the fields (planning the lesson, teaching new mathematical knowledge, classroom management and raising the level of interaction) due to scientific qualification.

There, the T value ranged from 0.021-1.771; and its statistical significance was greater than 0.05 . This indicates that there are no statistically significant differences in estimating the degrees of teaching practices in simultaneous virtual classes. This result is a sign of the similarity of practices in the field of lesson planning, teaching practices of new mathematical knowledge, classroom management practices, and raising the level of interaction for mathematics teachers, regardless of their academic qualification.

On the other hand, it was found that there were differences in the field of "evaluation", where the T value reached 2.776; and its statistical significance was less than the level of significance specified in the study (0.05). This means that there are statistically significant differences in favour of Bachelor's degree holders; since they enrolled in training and acquired skills that were reflected in their teaching practices, especially as they do not possess higher educational qualifications, a matter which contributed to their practice to a higher degree than those with higher qualifications; and most of the male and female teachers and school members have obtained a Bachelor's degree, which contributed to the similarity of their estimates for the teaching of mathematics.

\section{(C) Years of Experience}

To reveal the statistically significant differences in the degrees of estimating the status of teaching mathematics in simultaneous virtual classes in the light of the Covid 19 pandemic, which is attributed to (number of years of experience), the one-way ANOVA test was used, as in Table 10.

Table 10. Descriptive Differences between the levels of the teachers on their teaching practices in simultaneous virtual classes during Covid-19, due to their number of years of experience

\begin{tabular}{lllll}
\hline Field & Years of experience & N & Mean & SD \\
\hline Teaching planning & Less than 5 years & 45 & 2.70 & 0.48 \\
& From (5-10) years & 142 & 3.50 & 0.49 \\
& More than 10 years & 198 & 4.39 & 0.44 \\
Teaching new & Less than 5 years & 45 & 2.77 & 0.39 \\
mathematic & From (5-10) years & 142 & 3.42 & 0.30 \\
knowledge & More than 10 years & 198 & 4.33 & 0.34 \\
Class management & Less than 5 years & 45 & 2.58 & 0.56 \\
and raising interaction & From (5-10) years & 142 & 3.37 & 0.66 \\
level & More than 10 years & 198 & 4.14 & 0.63 \\
Evaluation & Less than 5 years & 45 & 2.80 & 0.32 \\
& From (5-10) years & 142 & 3.46 & 0.43
\end{tabular}




\begin{tabular}{lllll} 
& More than 10 years & 198 & 4.27 & 0.49 \\
\hline Total & Less than 5 years & $\mathbf{4 5}$ & $\mathbf{2 . 7 3}$ & $\mathbf{0 . 2 8}$ \\
& From (5-10) years & $\mathbf{1 4 2}$ & $\mathbf{3 . 4 4}$ & $\mathbf{0 . 2 2}$ \\
& More than 10 years & $\mathbf{1 9 8}$ & $\mathbf{4 . 3 0}$ & $\mathbf{0 . 3 1}$ \\
\hline
\end{tabular}

The results of Table 10 show that there are apparent differences between the arithmetic averages of the practices in teaching mathematics in virtual classes, according to the levels of the number of years of experience. To reveal the statistically significant differences between these averages, a one-way analysis of variance (ANOVA) was used, as shown in Table 11.

Table 11. Inferential Differences (ANOVA) between the levels of the teachers on the teaching practices in simultaneous virtual classes during Covid-19 due to their number of years of experience

\begin{tabular}{|c|c|c|c|c|c|c|}
\hline Field & $\begin{array}{l}\text { Sources of } \\
\text { variance }\end{array}$ & $\begin{array}{l}\text { Sum of } \\
\text { squares }\end{array}$ & $\begin{array}{l}\text { Degrees } \\
\text { of } \\
\text { freedom }\end{array}$ & $\begin{array}{l}\text { Mean of } \\
\text { squares }\end{array}$ & F-value & $\begin{array}{l}\text { p- } \\
\text { value }\end{array}$ \\
\hline \multirow[t]{3}{*}{$\begin{array}{l}\text { Teaching } \\
\text { planning }\end{array}$} & $\begin{array}{l}\text { Between } \\
\text { groups }\end{array}$ & 135.778 & 2 & 67.889 & 313.881 & 0.000 \\
\hline & $\begin{array}{l}\text { Within } \\
\text { groups }\end{array}$ & 82.622 & 382 & 0.216 & & \\
\hline & Total & 218.400 & 384 & & & \\
\hline $\begin{array}{l}\text { Teaching new } \\
\text { mathematic }\end{array}$ & $\begin{array}{l}\text { Between } \\
\text { groups }\end{array}$ & 123.486 & 2 & 61.743 & 554.909 & 0.000 \\
\hline \multirow[t]{2}{*}{ knowledge } & $\begin{array}{l}\text { Within } \\
\text { groups }\end{array}$ & 42.504 & 382 & 0.111 & & \\
\hline & Total & 165.990 & 384 & & & \\
\hline $\begin{array}{l}\text { Class } \\
\text { management }\end{array}$ & $\begin{array}{l}\text { Between } \\
\text { groups }\end{array}$ & 110.665 & 2 & 55.333 & 138.016 & 0.000 \\
\hline $\begin{array}{l}\text { and raising } \\
\text { interaction }\end{array}$ & $\begin{array}{l}\text { Within } \\
\text { groups }\end{array}$ & 153.149 & 382 & 0.401 & & \\
\hline level & Total & 263.814 & 384 & & & \\
\hline \multirow[t]{3}{*}{ Evaluation } & $\begin{array}{l}\text { Between } \\
\text { groups }\end{array}$ & 104.419 & 2 & 52.209 & 257.165 & 0.000 \\
\hline & $\begin{array}{l}\text { Within } \\
\text { groups }\end{array}$ & 77.553 & 382 & 0.203 & & \\
\hline & Total & 181.972 & 384 & & & \\
\hline \multirow[t]{3}{*}{ Total } & $\begin{array}{l}\text { Between } \\
\text { groups }\end{array}$ & 119.444 & 2 & 59.722 & 775.971 & 0.000 \\
\hline & $\begin{array}{l}\text { Within } \\
\text { groups }\end{array}$ & 29.400 & 382 & 0.077 & & \\
\hline & Total & 148.884 & 384 & & & \\
\hline
\end{tabular}

Table 11 shows that there are statistically significant differences at the level of significance $(\alpha \leq 0.05)$ between the averages of estimating teaching practices in simultaneous virtual classes for mathematics teachers, due to the variable number of years of experience. The value of $(\mathrm{F})$ on the overall practices was 775.971; and its statistical significance was less than the level of Significance (0.05). This indicates the existence of differences in the evaluation of teaching practices in simultaneous virtual classes for mathematics teachers; and this difference is attributed to experience. 
The results of Table 11 also show that there are statistically significant differences at the level of significance $(a \leq 0.05)$ in the fields (planning the lesson, teaching new mathematical knowledge, class management and raising the level of interaction, and evaluation) due to the number of years of experience. The $\mathrm{F}$ value ranged from 138.016-554.909; and its statistical significance was less than 0.05, a matter which indicates the existence of statistically significant differences in estimating the degrees of teaching practices in simultaneous virtual classes. To determine the direction of these differences, the Scheffe test was used for dimensional comparisons; and the results are shown in Table 12.

Table 12. Scheffe test results for averages, comparison of mathematics teaching practices in virtual classes, according to the levels of experience

\begin{tabular}{|c|c|c|c|c|c|}
\hline Field & $\begin{array}{l}\text { Years of } \\
\text { experience }\end{array}$ & $\begin{array}{l}\text { Mea } \\
\text { n }\end{array}$ & $\begin{array}{l}\text { Less } \\
\text { than } 5 \\
\text { years }\end{array}$ & $\begin{array}{l}\text { From (5- } \\
\text { 10) years }\end{array}$ & $\begin{array}{l}\text { More } \\
\text { than } 10 \\
\text { years }\end{array}$ \\
\hline \multirow[t]{3}{*}{$\begin{array}{l}\text { Teaching } \\
\text { planning }\end{array}$} & $\begin{array}{l}\text { Less than } 5 \\
\text { years }\end{array}$ & 2.70 & -- & -- & -- \\
\hline & $\begin{array}{l}\text { From }(5-10) \\
\text { years }\end{array}$ & 3.50 & $* 0.803$ & -- & -- \\
\hline & $\begin{array}{l}\text { More than } 10 \\
\text { years }\end{array}$ & 4.39 & *1.69 & *0.89 & -- \\
\hline $\begin{array}{l}\text { Teaching new } \\
\text { mathematic }\end{array}$ & $\begin{array}{l}\text { Less than } 5 \\
\text { years }\end{array}$ & 2.77 & --- & -- & -- \\
\hline \multirow[t]{2}{*}{ knowledge } & $\begin{array}{l}\text { From }(5-10) \\
\text { years }\end{array}$ & 3.42 & *0.65 & -- & -- \\
\hline & $\begin{array}{l}\text { More than } 10 \\
\text { years }\end{array}$ & 4.33 & *1.56 & ${ }^{*} 0.95$ & -- \\
\hline \multirow{2}{*}{$\begin{array}{l}\text { Class } \\
\text { management and } \\
\text { raising }\end{array}$} & $\begin{array}{l}\text { Less than } 5 \\
\text { years }\end{array}$ & 2.58 & --- & -- & -- \\
\hline & $\begin{array}{l}\text { From (5-10) } \\
\text { years }\end{array}$ & 3.37 & ${ }^{*} 0.78$ & -- & -- \\
\hline interaction level & $\begin{array}{l}\text { More than } 10 \\
\text { years }\end{array}$ & 4.14 & *1.56 & ${ }^{*} 0.77$ & -- \\
\hline \multirow[t]{3}{*}{ Evaluation } & $\begin{array}{l}\text { Less than } 5 \\
\text { years }\end{array}$ & 2.80 & --- & -- & -- \\
\hline & $\begin{array}{l}\text { From (5-10) } \\
\text { years }\end{array}$ & 3.46 & *0.66 & -- & -- \\
\hline & $\begin{array}{l}\text { More than } 10 \\
\text { years }\end{array}$ & 4.27 & *1.47 & $* 0.804$ & -- \\
\hline \multirow[t]{3}{*}{ Total } & $\begin{array}{l}\text { Less than } 5 \\
\text { years }\end{array}$ & 2.73 & -- & -- & -- \\
\hline & $\begin{array}{l}\text { From }(5-10) \\
\text { years }\end{array}$ & 3.44 & ${ }^{*} 0.71$ & --- & -- \\
\hline & $\begin{array}{l}\text { More than } 10 \\
\text { years }\end{array}$ & 4.30 & ${ }^{*} 1.57$ & ${ }^{*} 0.86$ & -- \\
\hline
\end{tabular}

The results of Table 12 show that there are statistically significant differences at the level of significance $(a \leq 0.05)$ in the overall degree and in the fields (lesson planning, teaching new mathematical knowledge, classroom management and raising the level of interaction, and evaluation). These differences are attributed to the number of years of experience in favor of male and female teachers, whose 
experience is more than (10) years compared to those with less than five years; and compared to those whose years of experience ranged from 5-10 years.

There were also differences in favor of the category of 5-10 years, when compared to those who had less than five years. These results may be attributed to the impact of the experience factor; since, as the male and female teachers pass the experiences in their years of teaching service, they gain knowledge and skill in teaching mathematics through virtual classes; where they have had opportunities to apply such knowledge during their years of teaching experience, in exchange for newly experienced male and female teachers.

\section{Discussion}

The Saudi Arabian kingdom Ministry of Education has taken careful steps to apply distance learning, in order to help limit the spread of COVID-19, by employing both synchronous and asynchronous learning in schools. However, the current study revealed a high degree in the status of teaching mathematics, from the point of view of male and female teachers, on the total score with the other studies. The reason for the appearance of the general result with a high degree may be attributed to the technical features that characterize the educational platform that supports the interactive teaching approach in virtual classes.

This study has implicitly agreed with the results of many studies that emphasized the impact of technological and technical preparations on the success of teaching through virtual classes in the light of the Covid 19 pandemic, such as the study of Adnan and Anwar (Adnan \& Anwar, 2020), which confirmed that online education cannot achieve its goals in poor countries, in which it is difficult for the citizens to access the Internet, due to technical and financial problems, as is the case in Pakistan.

Moreover, the study of O'Keefe et al., (2020) showed the progress of Saudi Arabia in 13 indicators out of 16 indicators on average of these countries. The study also revealed that teachers received great support to overcome obstacles in activating e-learning. The study also agreed with the results of Hassan's study (2020), which emphasized the role of electronic and interactive software in activating the educational platform. The study also agreed with the study of Al-Khamisi (2020), which emphasized the role of organizing teaching procedures in virtual classes, their schedule, and the evaluation methods.

This study also implicitly agreed with the results of Bodie (2009), who found that there is a high level of interactivity and a correlation between the teacher's behaviors and the educational method, a matter which contributed to increasing learners' satisfaction. It also agreed with the results of Lu's study (2011), which found that the use of virtual classes enhances communication in online mathematics teaching. It also tacitly agreed with the results of the Rigel and Kozen study (2016), which found that virtual classes may have many benefits to offer, rather than traditional ones in terms of acquiring and mastering the skills of the twenty-first century. 
Moreover, the study agreed with the results of Shoaib (2016), which revealed the existence of an effect of simultaneous versus asynchronous teaching in favor of simultaneous virtual classes. It also tacitly agreed with the results of AL-Ahmari (2019), which revealed the success of the Saudi Virtual School experience; and the results showed its reliance on simultaneous classes; and that there is a positive trend for students and teachers to learn by using such classes.

The results of the study of Al-Saeed and Al-Abed (2018) and the study of AlOmari and Ismail (2019) confirmed the effectiveness of using virtual classes in mathematics achievement, and in achieving professional practices among mathematics female teachers.

Based on the previous results and in the light of the researchers' experience in the field of teaching mathematics and their use of the educational platform during the Covid 19 pandemic, the preparedness and awareness of the Kingdom of Saudi Arabia's since before the Covid 19 pandemic on the importance of educational platforms and virtual learning, parallel to traditional learning and the readiness of the educational environment for the transmission of distance teaching contributed to the success of the idea of distance education, a matter which was reflected positively in their teaching experiences, as revealed by the results of the current study.

It has also confirmed the results of many studies that revealed the role of virtual class readiness in the success of distance education in various educational institutions. A good example is the study by Elzainy et al., (2020), which confirmed the effectiveness of the virtual classes and online assessment, as was also confirmed by the results of the study of Eddie and José (2020) that revealed the effectiveness of online mathematics learning activities for teachers in the COVID-19 time; and that the students demonstrated excellent online performance in acquiring mathematics learning skills in technology-rich environments.

The results of the study in this area reveal differences at the significance level (a $\leq 0.05$ ), as regards the teaching practices of mathematics teachers in simultaneous virtual classes during Covid-19, due to gender, academic qualification, and the number of years of experience. These results agreed with the results in the study of Elzainy et al. (2020), in which it was found that there was a statistically significant increase in the average scores of female students during the electronic sessions for problem-based learning compared to those of males.

While at the level of practices in other fields (lesson planning, teaching new mathematical knowledge, classroom management, and raising the level of interaction) there were no differences that appeared in the degree of practice; since the values of $\mathrm{T}$ ranged from 1.743 - 1.950; and its statistical significance exceeded the level of significance (0.05), a matter which indicates the similarity of practices between male and female teachers in the three fields. 
The reason for this may be attributed to the similar perceptions of mathematics teachers and the similarity of teaching practices in the simultaneous virtual classes of mathematics, regardless of gender, because of the similarity of conditions, school infrastructure and equipment, and the similarity of teaching strategies and those of evaluation and teaching practices.

\section{Conclusion}

Mathematics education has changed, due to the Covid-19 pandemic. Most countries in the world, including Saudi Arabia, have turned to teaching Mathematics through virtual education, after the schools were closed in those countries. Thus, the current study aimed to identify the status of teaching Mathematics in simultaneous virtual classes in the light of the Covid-19 pandemic, by uncovering the teaching practices in the fields of: - lesson planning, teaching the new mathematical knowledge, classroom management and raising the level of interaction and evaluation.

The descriptive approach was used in the study; and this involved a random sample of 385 teachers of Mathematics in the Qassim Education Department, which was chosen during the first semester of AY 2020/21. A questionnaire was used to collect the data after confirming the validity and reliability thereof.

The results of the study showed that the status of teaching Mathematics in simultaneous virtual classes in the light of the Covid-19 pandemic was at a high degree (3.80/5), according to the respondents' point of view, the results were as follows: - Planning "high"3.87", teaching new mathematical knowledge "high" 3.81 ", and class management and raising the level of interaction was at a high degree of " 3.67 ".

\section{Recommendations}

In the light of the results of the current study, the following recommendations can be made:

- The results of the study revealed that there is a discrepancy in some practices, a matter which requires identifying the training needs of mathematics male and female teachers in the field of e-learning in virtual classes, such as diversifying the methods of receiving students' responses to activities (chatting - WhatsApp --... etc.), the use of electronic participatory learning strategies in building and organizing the work of cooperative learning groups, employing electronic communication applications in providing reinforcement and feedback to students, employing electronic sports activities in presenting the lesson, and using virtual engineering tools, while solving the mathematical problems.

- Emphasizing the importance of continuing to maintain the level of practices that appeared to a high and very high degree in aspects related to teaching mathematics through virtual classes in the levels of planning the lesson, the acquisition of new mathematical knowledge, classroom management, interaction, and evaluation.

- Improving the practices of teaching mathematics in virtual classes that showed a moderate degree of practice, such as using three-dimensional 
models in displaying mathematical shapes and symbols, employing electronic games to develop various mathematical skills, using electronic means to communicate with the parents, and directing students to make reflective summaries, in order to link with the ideas of the lesson.

- Developing the skills of mathematics male and female teachers in the field of electronic design, such as mind maps and interactive videos, through the use of the educational platform.

- Enabling the teachers of gaining gaming skills and designing electronic games that would enhance mathematics learning.

\section{Limitations}

The limitations of this study focused on 385 male and female teachers, who were selected randomly. The study consisted of 283 male teachers and (102) female teachers from the entire population. Table 1 shows the characteristics of the sample of the study, according to the variables of gender, academic qualification, and the number of years of experience.

\section{References}

Abdel Wahab, F. (2007). The Effectiveness of a Proposed Program in Developing Selfefficacy and the Status of Mathematics Teaching Among Science Female Teachers before Service in the Sultanate of Oman. Journal of Scientific Education, 3(10), 215-263.

Abdallah, R., \& Wardat, Y. (2021). Teachers' perceptions on the effectiveness of professional development programs in improving the curriculum implementation at Jordanian schools. Elementary Education Online, 20(5), 44384449. https:// doi.org/10.17051/ilkonline.2021.01.126

Adnan, M., \& Anwar, K. (2020). Online learning Amid the COVID-19 Pandemic: Students' Perspectives. Journal of Pedagogical Sociology and Psychology, 2(1), 45-51.

Alarabi, K., \& Wardat, Y. (2021). UAE-based Teachers' Hindsight Judgments on Physics Education during the COVID-19 Pandemic. Psychology and Education Journal, 58(3), 2497-2511.

AL-Ahmari, A. (2019). Virtual Classes between Theory and Practice: A Study of the Experience of the Saudi Virtual School. Arab Journal of Literature and Human Studies, 6, 311-338.

AL-Anzi, A., \& Al-Massad, A. (2018). The Status of Using Technology in Teaching Mathematics for the Primary Stage in the Schools of the City of Ar'ar from the Point of View of Male and Female Teachers. The Arab Journal of Science and Research Publishing, 2(23), 1-22.

AL-Astal, O., \& AL-Farra, I. (2013). The Status of Using Virtual Classroom Technology in Teaching Educational Courses at Al-Quds Open University and the Ways to develop Them [M.A. thesis, College of Education, Al-Azhar University].

Al-Khamisi, A. (2020). Education in the Time of Coronavirus (COVID-19): Bridging the Gap between Home and School. International Journal of Research in Educational Sciences, $4(3), 52-73$.

Al-Najjar, T., \& Abu Shqair, M. (2014). The Effect of Employing Virtual Classes on Developing Computer and Internet Usage Skills Among Students of the College of Islamic Call [M.A. thesis, College of Education, Islamic University]. 
Al-Omari, K., \& Ismail, Z. (2019). The effectiveness of virtual classes in achieving professional practices among mathematics female teachers in intermediate level. Journal of Reading and Knowledge, 207, 286-314.

Al-Ruwais, A. (2011). The status of using technology in teaching mathematics from the point of view of its middle school teachers in the Kingdom of Saudi Arabia. Arab Gulf Resala Journal, 121, 15-56.

AL-Saeed, R., \& Al-Gharqi, W. (2015). "STEM": An Approach Based on Creative Projects to Develop Mathematics Education in Egypt and the Arab World. In the Fifteenth Annual Scientific Conference of the Egyptian Society for Mathematics Education Entitled: Teaching and Learning Mathematics and Developing Skills of the TwentyFirst Century, 133-149.

Al-Saeed, S., \& Al-Abed, A. (2018). The Effectiveness of Using Virtual Classes in Mathematics Achievement and Logical Thinking for Basic Tenth Grade Students [M.A. Thesis, College of Education, Sultan Qaboos University].

Bodie, L. (2009). An Experimental Study of Instructors in the Wimba Virtual Classroom [Doctoral dissertation, San Diego].

Eddie, M., \& José, M. (2020) Prospective Teachers' Online Learning Mathematics Activities in The Age of COVID-19: A Cluster Analysis Approach. EURASIA Journal of Mathematics, Science and Technology Education, 16(9), 15- 29.

Elzainy, A., El Sadik, A., \& Al Abdulmonem, W. (2020) Experience of E-Learning and Online Assessment During the COVID-19 Pandemic at the College of Medicine, Qassim University. Journal of Taibah University Medical Sciences, 15(6), 456-462

Hassan, I. (2020). Distance Learning and Teaching of Mathematics in the light of the Corona pandemic. International Journal of Research in Educational Sciences, 3(4), 337355.

Jarrah, A. M., Khasawneh, O. M., \& Wardat, Y. (2020). Implementing pragmatism and John Dewey's educational philosophy in Emirati elementary schools: case of mathematics and science teachers. International Journal of Education Economics and Development, 11(1), 58. https://doi.org/10.1504/ijeed.2020.104287

Khalil, I. A. (2021, March). Teaching Mathematics in Synchronized Virtual Classes: A Proposed Model in the Light of The Mathematical Power. In Proceedings of INTED2021 Conference (Vol. 8, p. 9).

Khalil, I., \& AL-Massad, A. (2016). Barriers to Mathematics Teachers When Using Sketchpad Interactive Software When Teaching Engineering Subjects Included in Middle School Courses. The International Journal of Specialized Education, 5(5), 83-97.

Alarabi, K., \& Wardat, Y. (2021). UAE-based Teachers' Hindsight Judgments on Physics Education during the COVID-19 Pandemic. Psychology and Education Journal, 58(3), 2497-2511.

Kotait, G. (2015). Modern Teaching and Learning Techniques. House of Culture for Publishing and Distribution.

Lu, Y. (2011). Using a Virtual Classroom to Teach Online Mathematics [Report]. ED519767

Martin, F., Parker, M., \& Allred, B. (2013). A Case Study on the Adoption and Use of Synchronous Virtual Classroom. The Electronic Journal of E-learning, 11(2), 124-138. 
O'Keefe, L., Dellinger, J. T., Scragg, B., Amelina, N., \& Mathes, J. (2020). The State of Online Learning in the Kingdom of Saudi Arabia: A COVID-19 Impact Study for K12 [Report]. Online Learning Consortium. https:// onlinelearningconsortium.org.

Obaid, W. (2016). Teaching Mathematics to all Children in the Light of the Requirements of Standards and the Culture of Thinking. Dar Al-Masirah.

Riegel, C., \& Kozen, A. (2016). Attaining 21st Century Skills in a Virtual Classroom. Educational Planning, 23(3), 41-55.

Shakman, K., Riordan, J., Sánchez, M. T., Cook, K. D., Fournier, R., \& Brett, J. (2012). An Examination of Performance-Based Teacher Evaluation Systems in Five States [Report]. Department of Education, Institute of Education Sciences, National Center for Education Evaluation and Regional Assistance, Regional Educational Laboratory Northeast and Islands.

Shoaib, I. M. (2016). The Effect of Different Types of Simultaneous / Asynchronous Virtual Classes on the Achievement and Development of the Skills of Producing Electronic Educational Games Among Female Kindergarten Students. Journal of Educational Sciences, Faculty of Graduate Studies, Cairo University, 24(1), 467-508.

Stoica, G., \& Wardat, Y. (2021). An Inequality Can Change Everything. The American Mathematical Monthly, 128(9), 810.

Wardat, Y., Jarrah, A. M., \& Stoica, G. (2021). Understanding the meaning of the equal sign: a case study of middle-school students in the United Arab Emirates. European Journal of Educational Research, 10(3), 1505-1514. https://doi.org/10.12973/eujer.10.3.1505

World Health Organization. (2020). Coronavirus Disease (Covid-19). https://www.who.int 